MenoN, I.S. (1967) Syncopal attacks in hypothyroid state. Journal of the Indian Medical Association, 48, 126.

SANDERS, V. (1962) Neurological manifestations of myxoedema. New England Journal of Medicine, 266, 599.

Vanhaelst, L., Neve, P., Chailly, P. \& Bastenie, P.A.
(1967) Coronary artery disease in hypothyroidism. Lancet. ii, 800 .

Winawer, S.J., Rosen, S.M. \& CoHn, H. (1963) Myxoedema coma with ventricular tachycardia. Archives of Internal Medicine, 111, 647.

\title{
Fibrosing alveolitis and active chronic hepatitis without hyperglobulinaemia
}

\author{
R. B. HudDY \\ B.M., M.R.C.P.
}

\author{
A. Ahmed \\ M.B., Ch.B.
}

\section{Manchester Royal Infirmary, Manchester, 13}

CASES of fibrosing alveolitis and active chronic hepatitis are rare. The small series reported by Turner-Warwick (1968) all had raised globulins, the range being from $4.0 \mathrm{~g} / 100 \mathrm{ml}$ to $5.8 \mathrm{~g} / 100 \mathrm{ml}$. We report a case in which the diagnosis was made in life and confirmed at necropsy, in whom the serum globulin level remained persistently normal.

\section{Case report}

The patient was a 61-year-old woman who presented in 1965 with a short history of cough and dyspnoea. Her chest X-ray at that time showed fairly widespread diffuse shadowing which was thought at first to be inflammatory, but showed little resolution after courses of treatment with penicillin and tetracycline. Tuberculosis was excluded by repeated sputum cultures. A diagnosis of idiopathic pulmonary fibrosis was made, and she was followed up for a time, but her symptoms did not progress. In 1968 she presented with a single, enlarged supraclavicular lymph node. This was excised and the histological appearance showed caseating granulomata. However, no acid-fast bacilli were seen on the sections. Nevertheless, she received 12-months' treatment with anti-tuberculous therapy. At the end of this time she was referred for review and further investigations of her chest condition, mainly because of the abnormal chest X-ray, though this had changed little over the years. She was fully investigated in July 1969.

Clinical examination revealed clubbing of the fingers, crepitations at the lung bases and a liver enlarged three fingers. Chest X-ray appearances, spirometry, $\mathrm{PaO}_{2}$ estimations at rest and after exercise and estimation of transfer factor (Table 1) all pointed clearly to a diagnosis of fibrosing alveolitis, but lung biopsy was not considered justifiable. The finding of hepatic enlargement did not at first suggest lupoid hepatitis; there was no history of jaundice, serum bilirubin was normal, spider naevi were not present and there was no splenomegaly. Liver function tests gave normal results for albumin and globulin, with normal electrophoretic strip and immune globulins, the level for the latter being as follows: IgG, $1300 \mathrm{mg} / 100 \mathrm{ml} ; \mathrm{IgA}, 170 \mathrm{mg} / 100 \mathrm{ml}$; IgM, $100 \mathrm{mg} / 100 \mathrm{ml}$. Serum transaminases and alkaline phosphatase were raised (44 KA Units $/ 100 \mathrm{ml}$ ) and 5-nucleotidase was grossly raised (148 Units). Tests for the LE phenomenon were positive, antinuclear factor was positive, smooth-muscle antibodies were positive at a titre of one in four, but thyroid antibodies, mitochondrial antibodies, tests for rheumatoid factor and Australia antigen were negative. Liver biopsy was carried out, and showed the characteristic appearances of active chronic hepatitis.

Treatment. In August 1969 treatment was started with prednisolone in a dose of $60 \mathrm{mg}$ daily, reducing over the course of the next 4 weeks to $20 \mathrm{mg}$ daily and maintaining this dose thereafter. There was some subjective improvement, though lung function tests did not change, and the ESR, which had previously been moderately raised, fell to normal, alka-

TABLE 1.

\begin{tabular}{lllc}
\hline & \multicolumn{1}{c}{ Initial values } & $\begin{array}{c}\text { After treatment } \\
\text { with steroids }\end{array}$ & $\begin{array}{c}\text { After treatment } \\
\text { with azathioprine }\end{array}$ \\
\hline Vital capacity & $1.31 / \mathrm{min}$ & $1.57 \mathrm{l} / \mathrm{min}$ & $1.55 \mathrm{l} / \mathrm{min}$ \\
FEV $_{1}$ & Normal & Normal & Normal \\
Transfer factor & $5.0 \mathrm{ml} \mathrm{CO} / \mathrm{min} / \mathrm{mmHg}$ & Unchanged & Unchanged \\
\hline
\end{tabular}


line phosphatase fell, 5-nucleotidase fell markedly, and transaminases fell while on the high steroid dose, but rose when this was reduced. In September azathioprine was added, in a dose of $200 \mathrm{mg}$ daily, reducing to $100 \mathrm{mg}$ daily after the first week. Thereafter she deteriorated steadily, subjectively at first, but in October becoming jaundiced. The alkaline phosphatase rose, and 5-nucleotidase rose to very high levels (248 Units). Towards the end of October, she developed abdominal pain and vomiting, the jaundice deepened and she died.

Necropsy. Deep jaundice was present, the liver was reduced in size $(950 \mathrm{~g})$ deeply bile-stained, with areas of external nodularity. Microscopic appearances showed persistent inflammatory-cell infiltration of the portal tracts which was much less marked than in the biopsy specimen. There was distortion of the lobular pattern, but regenerating nodules were not seen. The lungs were reddish-grey in colour, rubbery in consistency and showed generalized 'honey-comb' appearances (Fig. 1). Microscopically, there was widespread reticular thickening and destruction of the alveolar walls, with fibrosis, and in places a mononuclear exudate, the appearances being those of fibrosing alveolitis. Acute duodenal ulceration was present and death was due to a perforated gastric ulcer, undoubtedly the result of steroid treatment.

\section{Discussion}

The diagnosis in this case was made during life. The absence of jaundice and the asymptomatic

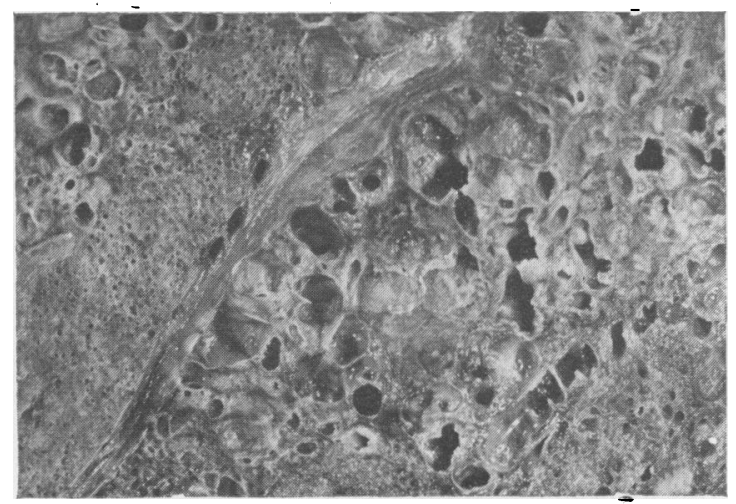

FIG. 1. Macroscopic appearance of lungs. nature of the hepatic disease was noted, as in TurnerWarwick's cases. Jaundice, together with the presence of spider naevi and splenomegaly, is considered ${ }_{c}^{\varrho}$ to be frequent in lupoid hepatitis (Sherlock, 1968). In each of Turner-Warwick's cases, there was ano abnormality of at least one of the immune globulins.0 The globulin levels in this patient varied betweeno $2.3 \mathrm{~g} / 100 \mathrm{ml}$ and $3.2 \mathrm{~g} / 100 \mathrm{ml}$ on seven occasions during the period of observation and treatment; $;$ immune globulins were normal. Apart from then absence of hyperglobulinaemia, there was goods evidence of an auto-immune process, with several. positive tests for auto-antibodies, the presence of $\overrightarrow{\vec{\omega}}$ lymphoid infiltration, multi-system involvement ando response to steroids. Comparison of the necropsyo histology with the biopsy specimen of liver suggested 3 . that some improvement had occurred in this case. It seems unlikely that the lungs improved at all. Their use of azathioprine in the treatment of lupoid hepatitis has been reported on a number of occasionsis (Mackay, Weiden \& Ungar, 1964; Rastogi, Deodhar \& Brown, 1967; Mackay, 1968) but there was no convincing evidence that the treatment was moreeffective than prednisolone. Deterioration in this $=$ patient coincided with the use of azathioprine. Whend on the steroids alone, she improved subjectively and in respect of the alkaline phosphatase, transaminases and 5-nucleotidase. Following the exhibition 5 f azathioprine, she developed jaundice, the alkal phosphatase rose, and 5-nucleotidase rose to as dramatically high level. It is not at all clear why this occurred. Bearing in mind the theory that azathioprine, along with other immunosuppressives, exerts? its action by selectively removing the clone of abnor $\overrightarrow{\vec{D}}$ mal lymphocytes responsible for the auto-immune process, our experience would tend to support the view that the drug is best avoided in cases in which. the globulins are normal.

\section{References}

MACKay, I.R., WeIden, S. \& UNGaR, B. (1964) Treatment of active chronic hepatitis and lupoid hepatitis with $6 \frac{\mathrm{O}}{3}$ mercaptopurine and Azathioprine. Lancet, i, 899.

MACKAY, I.R. (1968) Chronic hepatitis: effect of prolonged suppressive treatment and comparison of azathioprine with prednisolone. Quarterly Journal of Medicine, 147, 3790

Rastogi, H., Deodhar, S.D. \& Brown, C.H. (1967) Treat ment of lupoid hepatitis with azathioprine. Cleveland Clinic Quarterly, 34, 97.

SHERLOCK, S. (1968) Diseases of the Liver and Biliary System N 4th edn, p. 428, Blackwell Scientific Publications, Oxfordñ

TURNER-WARWICK, M. (1968) Fibrosing alveolitis and chronic్ liver disease. Quarterly Journal of Medicine, 145, 133. 